\title{
Reactions of alpha-nucleophiles with a model phosphate diester
}

\author{
Anthony J. Kirby, *Alex M. Manfredi, Bruno S. Souza, Michelle Medeiros, Jacks P. Priebe, \\ Tiago A. S. Brandão and Faruk Nome* \\ University Chemical Laboratory, Cambridge and Departamento de Química, \\ Universidade Federal de Santa Catarina, Florianópolis, SC, 88040-900, Brazil \\ E-mail:ajk1@cam.ac.uk; faruk@qmc.ufsc.br
}

We dedicate this paper to Prof. Harri Lönnberg on the occasion of his $60^{\text {th }}$ birthday, in recognition of his many lasting contributions to Bioorganic Chemistry.

\begin{abstract}
Substantial rate enhancements are observed for the reactions of $\alpha$-effect nucleophiles with 2,4dinitrophenyl ethyl phosphate diester 4. The effect is largest (ca. 4500-fold) for the hydroperoxide anion. However, the most reactive $\alpha$-effect nucleophile, and thus the most reactive nucleophile towards phosphate phosphorus at $\mathrm{pHs}$ near to or above its $\mathrm{p} K_{\mathrm{a}}$ of 13.74 , is the hydroxylamine anion $\mathrm{NH}_{2} \mathrm{O}^{-}$. The kinetic reactivities of the $\alpha$-effect nucleophiles follow a Brønsted correlation, with a slope $\beta_{\text {nuc }}=0.41 \pm 0.03$ greater than that $(0.30)$ observed for non- $\alpha$ effect nucleophiles, consistent with a thermodynamic origin for the effect.
\end{abstract}

Keywords: Phosphate diester, alpha-effect, nucleophilic reactivity, Brønsted

\section{Introduction}

The use of Brønsted relationships to correlate nucleophilic reactivity with basicity provides a simple procedure for the identification of special cases. We have been interested over many years in the $\mathrm{S}_{\mathrm{N}} 2(\mathrm{P})$ reactions of phosphate esters, where reactivity depends not only on the nucleophile and the leaving group, but also, in the cases of tri- and diesters, on the "spectator group" or groups ( $\mathrm{RO}, \mathrm{R}^{\prime} \mathrm{O}$ in Scheme 1). 


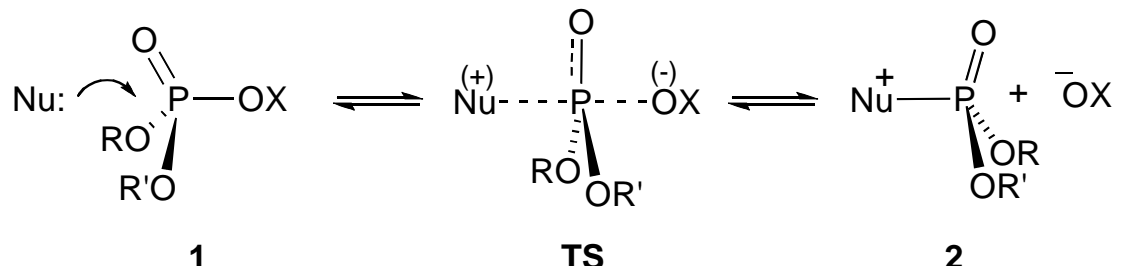

Scheme 1. Generalized reaction scheme for the $\mathrm{S}_{\mathrm{N}} 2(\mathrm{P})$ reactions of phosphate esters. $\mathrm{X}=\mathrm{R}, \mathrm{Ar}$ or (in pyro- or polyphosphates) a second phosphoryl center: R and/or R' can be an alkyl or aryl group, a proton or a negative charge.

Representative published Brønsted relationships for the three classes of phosphate esters (with the same good leaving group) are summarized in Table 1 . The $\mathrm{S}_{\mathrm{N}} 2(\mathrm{P})$ reactions of monoester dianions (i), observed only for neutral nucleophiles, are typically most dependent on, and thus primarily driven by, the leaving group: when this is sufficiently good the dependence on basicity of the second order rate constant for the reaction with the nucleophile, as measured by the Brønsted parameter $\beta_{\text {nuc }}$, may disappear. ${ }^{1}$ Bond formation to both nucleophile and leaving group is thus weak, in what can be (loosely!) described as a "loose" transition state (TS in Scheme 1), with bonding to the nucleophile not significantly stronger than its hydrogen-bonding solvation. ${ }^{2}$ The $\mathrm{S}_{\mathrm{N}} 2(\mathrm{P})$ reactions of triesters (iii) by contrast depend strongly on both nucleophile and leaving group, and evidently involve tighter transition states. The story is complicated for triesters by the possibility that a pentacovalent intermediate may be involved in at least some systems: in which case TS (Scheme 1) would normally represent the transition state for its formation. Interestingly there is a marked difference in the Bronsted $\beta_{\text {nuc }}$ values for the reactions with oxyanion and amine nucleophiles. Thus the simple expectation that $\beta_{\text {nuc }}$ values for the reactions of diesters (ii) should lie between those for mono- and triesters is not supported, at least for amine nucleophiles.

Table 1. Brønsted parameters $\beta_{\text {nuc }}$ for the reactions of 2,4-dinitrophenyl phosphate esters $\left(\mathbf{1}, \mathrm{X}=2,4\right.$-dinitrophenyl) with nucleophiles. ${ }^{1}$

\begin{tabular}{lll}
\hline Esters & $\begin{array}{l}\beta_{\text {nuc }} \\
\text { (oxyanion nucleophiles) }\end{array}$ & $\begin{array}{l}\beta_{\text {nuc }} \\
\text { (pyridine nucleophiles) }\end{array}$ \\
\hline (i) $\mathbf{A r O}-\mathbf{P O}_{3}{ }^{=1}$ & No reaction observed & 0 \\
(ii) $\mathbf{A r O}-\mathbf{P O}_{2} \mathbf{O M e}{ }^{-3}$ & 0.30 & 0.30 \\
(iii) $\mathbf{A r O}-\mathbf{P O}(\mathbf{O R})_{2}{ }^{a, 4}$ & 0.30 & $0.61^{b}$
\end{tabular}

${ }^{a} \mathrm{R}=\left(\mathrm{CH}_{2}\right)_{3} .{ }^{b}$ A possible complication is the (mostly minor) contribution of general base catalysis to the reactions of pyridines with triesters. We note that any such contribution would have the effect of increasing the apparent value of $\beta_{\text {nuc. }}$. 
Differences in the behavior of nucleophiles based on different element centers are not unusual for reactions at phosphorus. The fluoride anion, for example, is well known to be a significantly stronger nucleophile than an oxyanion of the same $\mathrm{p} K_{\mathrm{a}}$, a property usually interpreted in terms of the exceptional strength of the $\mathrm{P}-\mathrm{F}$ bond; that is to say, to thermodynamic factors. ${ }^{5}$ The difference in behaviour of oxyanion and pyridine nucleophiles in their $\mathrm{S}_{\mathrm{N}} 2(\mathrm{P})$ reactions with triesters apparent in Table 1 could have a similar origin; although in this case there are no obvious differences in reactivity with the activated esters involved. ${ }^{4}$

Nucleophiles showing enhanced reactivity in $\mathrm{S}_{\mathrm{N}} 2(\mathrm{P})$ reactions are interesting in themselves, and also potentially useful in clean-up operations involving organophosphorus toxins. ${ }^{6}$ Most interesting, and potentially most useful, are the so-called $\alpha$-nucleophiles. These are reactants familiar examples are hydroxylamine and the hydroperoxide anion - characterized by an electronegative atom with unshared (lone-pair) electrons adjacent (alpha) to the nucleophilic center. $^{5,7}$ The magnitude of the effect depends on the type of electrophile under attack, and is greater for reactions at harder centers, and also on their intrinsic reactivity. Table 2 shows typical values for the $\alpha$-effect for reactions of hydroxylamine with 2,4-dinitrophenyl phosphate esters: the rate enhancements follow the sensitivity to the nucleophile. The more recent values in the final column are for the reactions of the naphthol esters 5 (see below).

Table 2. $\alpha$-Effects compared, for reactions of hydroxylamine with 2,4-dinitrophenyl phosphate esters (1, X =2,4-dinitrophenyl) and phosphate esters (5) of 8-dimethylammonium-1-naphthol.

\begin{tabular}{|c|c|c|}
\hline \multirow[b]{2}{*}{ Esters } & \multicolumn{2}{|c|}{$\alpha$-effects for $\mathrm{NH}_{2} \mathrm{OH}^{b}$} \\
\hline & for esters 3 & for esters $\mathbf{5}$ \\
\hline (i) $\mathrm{ArO}-\mathrm{PO}_{3}{ }^{=1}$ & $<10$ & $3^{8}$ \\
\hline (ii) $\mathrm{ArO}-\mathrm{PO}_{2} \mathrm{OMe}^{-3}$ & 70 & $25^{9}$ \\
\hline (iii) $\operatorname{ArO}-\mathbf{P O}(\mathbf{O R})_{2}{ }^{a, 4}$ & 700 & $100^{10}$ \\
\hline
\end{tabular}

${ }^{a}(\mathrm{RO})_{2}=\left(\mathrm{CH}_{2}\right)_{3} \cdot{ }^{b}$ Estimated rate enhancements for reactions with $\mathrm{NH}_{2} \mathrm{OH}$. The comparison is with rates expected for primary amines $\mathrm{NH}_{2} \mathrm{R}$ of the same $\mathrm{p} K_{\mathrm{a}}$.

We have been interested in recent years in the reactions of nucleophiles with the series of phosphate esters 5 ( $\mathrm{R}=$ alkyl, a proton or a negative charge) of 8-dimethylammonium-1naphthol. Although the phosphorus centres are intrinsically much less reactive than those of the corresponding 2,4-dinitrophenyl esters 3 and 4, these compounds show comparable reactivity towards nucleophiles, by virtue of the efficient general acid catalysis provided by the neighboring general acid. However, the reactions of esters 5 with hydroxylamine show $\alpha$-effects which are significantly smaller, though following the usual sequence triester $>$ diester $>$ monoester dianion (Table 2). 


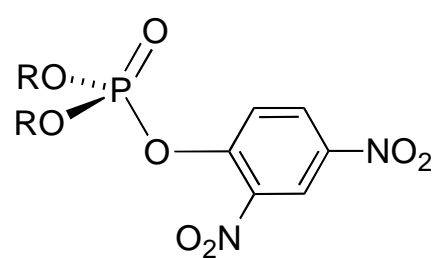

3

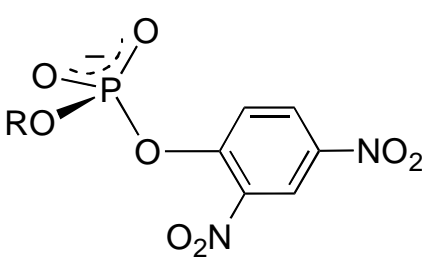

4

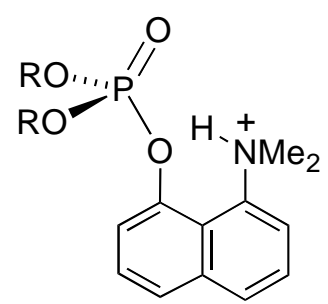

5

In the course of this work we found that there are no extensive data available for the reactions of $\alpha$-nucleophiles with phosphate diesters. Published investigations typically involve the reactions of the more reactive neutral triesters or phosphonate esters. ${ }^{11-13}$ So we have studied the reactions of a series of typical $\alpha$-effect nucleophiles with the model diester 2,4-dinitrophenyl ethyl phosphate $4(\mathrm{R}=\mathrm{Et})$, chosen to allow direct comparison with the extensive data available for its reactions with ordinary nucleophiles. ${ }^{3}$

\section{Results and Discussion}

We have collected data, at $25^{\circ} \mathrm{C}$ and ionic strength $1.0 \mathrm{M}(\mathrm{KCl})$, for the reactions of 4 ( $\left.\mathrm{R}=\mathrm{Et}\right)$ with seven representative $\alpha$-effect nucleophiles, including a comprehensive $\mathrm{pH}$-rate profile (Figure 1) for its reactions with hydroxylamine. $\mathrm{NH}_{2} \mathrm{OH}$ can react as a nucleophile in three different forms in the $\mathrm{pH}$ region, and all three of these (Scheme 2) appear to be highly reactive. Reactions of the neutral form with phosphate esters typically result in the formation of the $O$ phosphorylated product, and probably involve the ammonia oxide tautomer $\mathrm{NH}_{3}{ }^{+}-\mathrm{O}^{-} ;{ }^{-14}$ while at high $\mathrm{pH}$ the hydroxylamine anion is the most reactive $\alpha$-effect nucleophile - and hence the most reactive of all nucleophiles towards phosphate phosphorus.

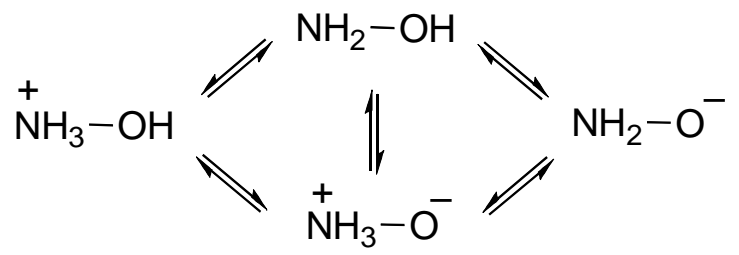

Scheme 2. Hydroxylamine can react as a nucleophile in three different forms: through nitrogen as the neutral species, especially with carbonyl compounds, through oxygen as the anion (at high $\mathrm{pH})$, and apparently also as the ammonia oxide zwitterion. ${ }^{14}$

The $\mathrm{pH}$-independent region (Figure 1) for the reaction of hydroxylamine with $4(\mathrm{R}=\mathrm{Et})$ between pH 7-10 represents the reaction of the overall neutral species $\mathrm{NH}_{2} \mathrm{OH} \rightleftharpoons \mathrm{NH}_{3}{ }^{+}-\mathrm{O}^{-}$; while the increasing rate at higher $\mathrm{pH}$ follows the increasing contribution of the reaction of the anion $\mathrm{NH}_{2} \mathrm{O}^{-}$. Because of the high $\mathrm{p} K_{\mathrm{a}}$ of the hydroxylamine $\mathrm{OH}$ group (13.74) the plateau rate 
for the anion reaction is not reached in the $\mathrm{pH}$ region. A further complication is that the reaction (between two anions) becomes very sensitive to ionic strength in this region: the details are discussed in the experimental section.

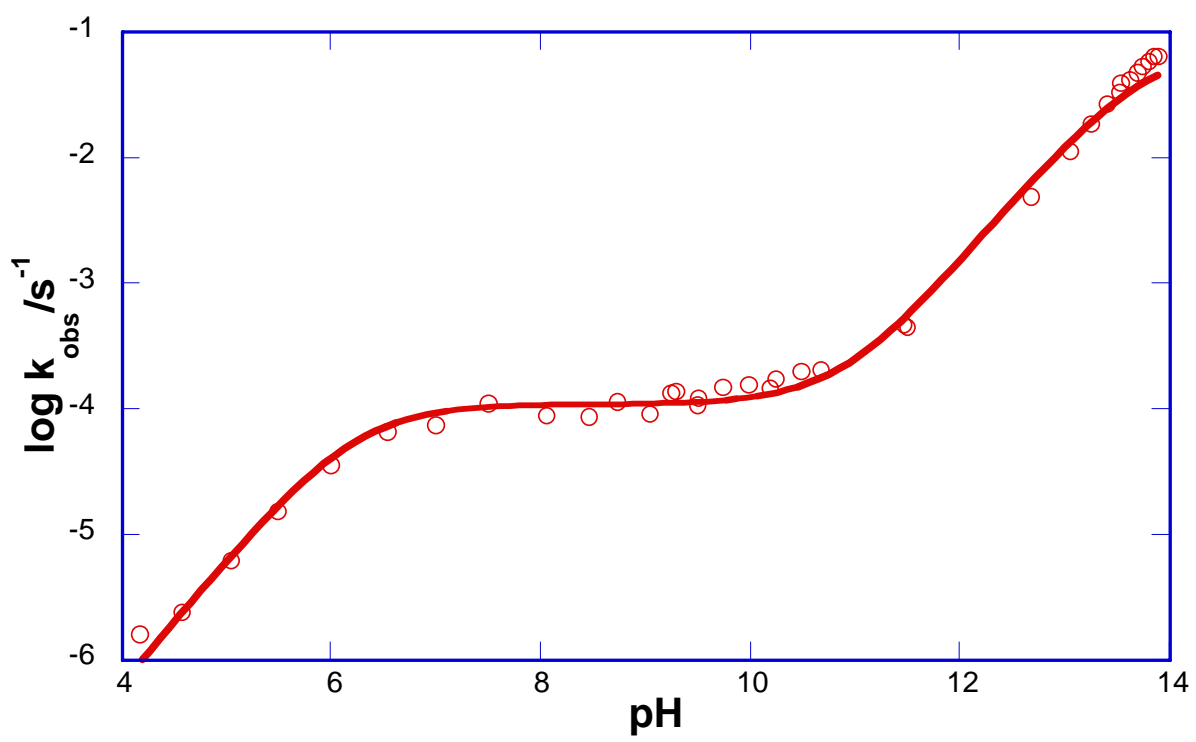

Figure 1. $\mathrm{pH}$-rate profile for the reaction of $4(\mathrm{R}=\mathrm{Et})$ with hydroxylamine (total concentration $=$ $0.4 \mathrm{M})$ at $25^{\circ} \mathrm{C}$ and ionic strength $1.0 \mathrm{M}(\mathrm{KCl})$. Points are experimental, the curve calculated using the constants in Table 3. The points at high $\mathrm{pH}$ (where the reaction with hydroxide is negligible), which show positive deviations from the calculated curve, represent extrapolations to zero ionic strength.

We discuss here specifically reactions involving nucleophilic attack on phosphorus. The phosphate transfer reactions of 2,4-dinitrophenyl phosphodiesters are slow enough that for some nucleophiles competition from nucleophilic aromatic substitution becomes significant. Thus 4 $(\mathrm{R}=\mathrm{Et})$ reacts with hydroxylamine and some of its methylated derivatives to give comparable amounts of $\mathrm{S}_{\mathrm{N}} 2(\mathrm{P})$ and $\mathrm{S}_{\mathrm{N}} \mathrm{Ar}$ products, as discussed in the experimental section. The data in the Tables have been corrected for these side reactions.

Second order rate constants for the reactions of $\mathbf{4}$ with the seven $\alpha$-effect nucleophiles studied in this work are shown in Table 3, and relevant comparisons of reactivity illustrated in the derived Brønsted plot (Figure 2). The (least squares) line drawn through the points for the $\alpha$ effect nucleophiles has a slope $\left(\beta_{\text {nuc }}\right)$ of $0.41 \pm 0.03$. This figure is significantly greater than the values of 0.30 observed for the reactions of both amine and oxygen nucleophiles with 2,4dinitrophenyl methyl phosphate at $39^{\circ} \mathrm{C}$, suggestive of stronger bonding in the transition state to the phosphorus centre from the $\alpha$-effect nucleophile. The published data for the methyl ester included in the plot (open symbols, dashed line) show that the behavior of the ethyl ester 4 ( $\mathrm{R}=$ Et) is quantitatively closely similar: the ca. 3-fold difference in rate constants being accounted for almost entirely by the different temperatures of the measurements. The point for fluoride ${ }^{3}$ is 
included to show how closely its enhanced reactivity matches that of the $\alpha$-effect nucleophiles. ${ }^{5}$ Methoxyamine, which cannot react through oxygen, shows, as usual, ${ }^{9}$ a significantly smaller $\alpha$ effect: as does hydrazine, perhaps for the same reason. The most reactive nucleophile is the anion of hydroxylamine $\mathrm{NH}_{2} \mathrm{O}^{-}$, though the largest $\alpha$-effect is observed for the peroxide anion $\mathrm{HOO}^{-}$, which is only 2.4 times less reactive though over two orders of magnitude less basic. Similar conclusions were reached for the reactions with a phosphate triester by Simanenko et al., who studied the reactions of a series of mostly inorganic $\alpha$-effect nucleophiles with several types of activated ester. ${ }^{12}$

Table 3. Second order rate constants for the $S_{N} 2(P)$ reactions of $\alpha$-effect [and related] nucleophiles with phosphate diester 4 , at $25^{\circ} \mathrm{C}$ and ionic strength $1.0 \mathrm{M}(\mathrm{KCl})$

\begin{tabular}{|c|c|c|c|c|}
\hline Nucleophile & $\mathbf{p} K_{\mathrm{a}}$ & Runs & $k_{2}, M^{-1} s^{-1}$ & $\begin{array}{l}\text { Magnitude of } \\
\alpha_{\text {-effect }}{ }^{b}\end{array}$ \\
\hline$\left[\mathrm{H}_{2} \mathrm{O}\right]$ & -1.54 & & $1.9 \times 10^{-9}$ & - \\
\hline $\mathrm{NH}_{2} \mathrm{OMe}$ & 4.6 & 8 & $7.75 \pm 0.02 \times 10^{-6}$ & 120 \\
\hline $\mathrm{Me}_{2} \mathrm{NOH}$ & 5.20 & 5 & $8.43 \pm 0.18 \times 10^{-5}$ & \\
\hline $\mathrm{NH}_{2} \mathrm{OH}^{c}$ & 5.96 & 14 & $1.48 \pm 0.02 \times 10^{-4}$ & 440 \\
\hline $\mathrm{MeNHOH}^{d}$ & 6.18 & 6 & $3.25 \pm 0.13 \times 10^{-4}$ & 830 \\
\hline $\mathrm{NH}_{2} \mathrm{NH}_{2}{ }^{e}$ & 7.98 & 12 & $1.18 \pm 0.02 \times 10^{-3}$ & 830 \\
\hline $\mathrm{HOO}^{-}$ & 11.65 & 6 & $7.74 \pm 0.27 \times 10^{-2}$ & 4500 \\
\hline $\mathrm{NH}_{2} \mathrm{O}^{-}$ & 13.74 & $16^{a}$ & $0.189 \pm 0.043$ & 2590 \\
\hline$\left[\mathrm{OH}^{-}\right]$ & 15.54 & & $2.57 \pm 0.11 \times 10^{-4}$ & - \\
\hline$\left[\mathrm{F}^{-}\right]^{f}$ & 3.17 & & $3.20 \times 10^{-5}$ & {$[630]^{c}$} \\
\hline
\end{tabular}

${ }^{a}$ Number of points at $\mathrm{pH}>12$ in Figure $1 .{ }^{b}$ Estimated rate enhancements, compared with the extrapolated rate for the reaction of an oxyanion of the same $\mathrm{p} K_{\mathrm{a}}$ (lower solid line in Figure 2). ${ }^{c}$ Corrected figure: $40 \%$ of reaction involves aromatic nucleophilic displacement. ${ }^{d}$ Corrected figure: $60 \%$ of reaction involves aromatic nucleophilic displacement. ${ }^{e}$ Statistically corrected. $f$ The rate for fluoride, and its calculated rate enhancement, are based on its reaction with 2,4dinitrophenyl methyl phosphate at $39^{\circ} \mathrm{C}$. ${ }^{3,12}$

The Brønsted plot of Figure 2 shows that the data for the $\alpha$-effect nucleophiles, including the points for the hydroperoxide and hydroxylamine anions, define a separate but recognisable linear correlation, with a slope $\left(\beta_{\text {nuc }}\right)=0.41 \pm 0.03$ which is greater than that correlating "normal" nucleophiles. We find a similar result for the reactions of the activated triester $5 .{ }^{10}$ Two points of interest arise from this observation. 1. There is no evidence in the case of neutral hydroxylamine for "anomalously high reactivity even among the series of inorganic $\alpha$-nucleophiles," 12 which seems to have arisen from mis-plotting its $\mathrm{p} K_{\mathrm{a}}$. 2. The slope of the Brønsted correlation (top line, Figure 2), which includes both neutral and anionic $\alpha$-nucleophiles, all reacting, we believe, through oxygen, is greater $\left(\beta_{\text {nuc }}=0.41\right.$ compared with 0.30$)$, rather than smaller than that for 
non- $\alpha$-effect nucleophiles. This is consistent with the origin of the $\alpha$-effect being thermodynamic, depending on the ultimate strength of the nucleophile-phosphorus bond being formed as well as its degree of formation. (Correcting for the different $\mathrm{p} K_{\mathrm{a}} \mathrm{s}$ of the $\mathrm{OH}$ and $\mathrm{N}^{+} \mathrm{H}$ groups of $\mathrm{R}_{2} \mathrm{~N}^{+} \mathrm{H}-\mathrm{OH}$ will affect $\log k_{2}$ values equally, and not affect the slope of the line.)

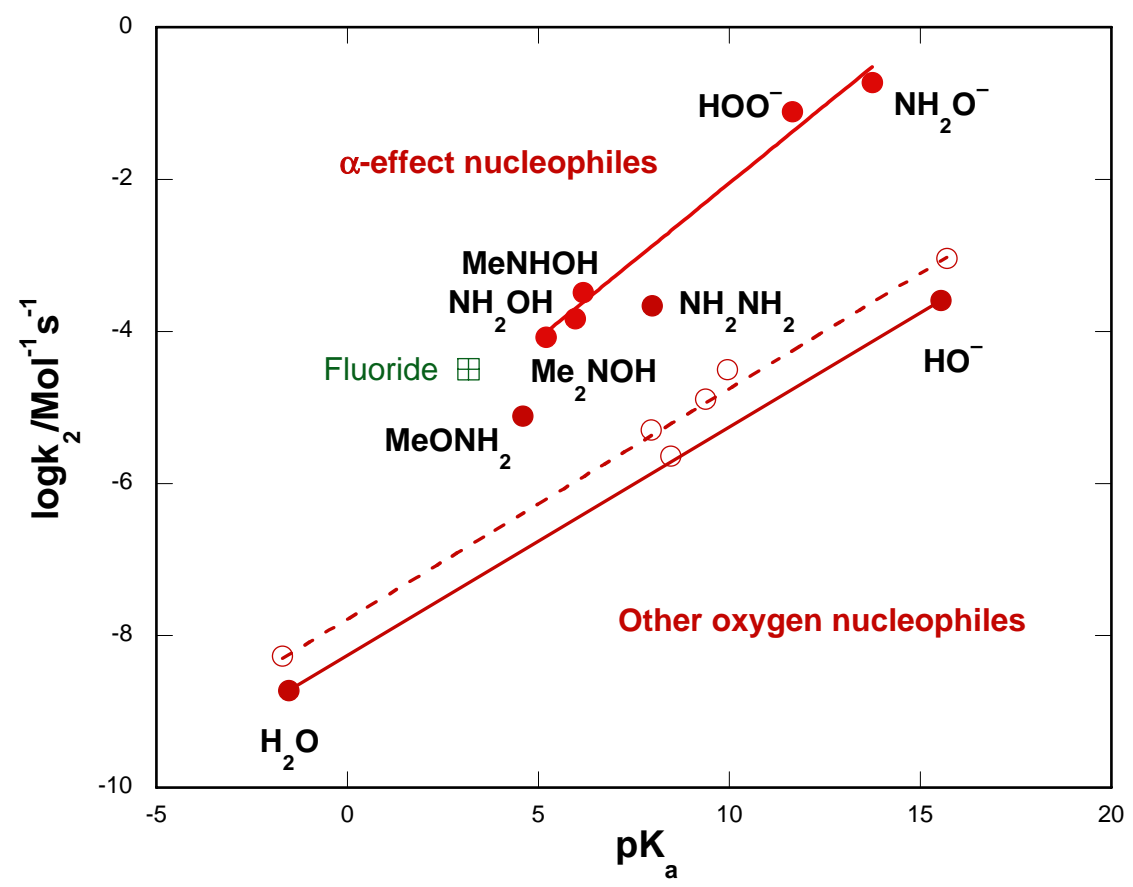

Figure 2. Brønsted relationships compared for reactions of $\alpha$-effect and other nucleophiles with alkyl 2,4-dinitrophenyl phosphate diesters. Data for reactions of 4 ( $\mathrm{R}=\mathrm{Et}$, filled circles) are from this work at $25{ }^{\circ} \mathrm{C}$. Points for fluoride and (open circles) the water, hydroxide and aryloxide anions are for reactions with 2,4-dinitrophenyl methyl phosphate at $39{ }^{\circ} \mathrm{C}$. ${ }^{3}$ See the text.

We note from Figure 2 that the seven $\alpha$-effect nucleophiles studied in this work fall into two groups. The two - methoxyamine and hydrazine - that can only react through nitrogen; and the five that can also - and do - react through oxygen. The Brønsted slope $\beta_{\text {nuc }}=0.41 \pm 0.03$ is defined by the line drawn through the points for the five oxygen nucleophiles. Separate Brønsted correlations for data for different types of nucleophile are normal, and provide evidence that the reactions concerned involve nucleophilic rather than general base catalysis. ${ }^{15}$

\section{Experimental Section}

General Procedures. The hydroxylamines (as their hydrochlorides), other nucleophiles, and inorganic salts were of the highest purity available and were used as purchased. ${ }^{1} \mathrm{H}$ and ${ }^{31} \mathrm{P}$ NMR spectra were recorded on a BRUKER Avance AM 250 spectrometer at $300 \mathrm{~K}$, operating at 250 
and $101 \mathrm{MHz}$ for ${ }^{1} \mathrm{H}$ and ${ }^{31} \mathrm{P}$, and using tetramethylsilane and $85 \% \mathrm{H}_{3} \mathrm{PO}_{4}$ as internal and external standards, respectively. Chemical shifts are reported in $\delta(\mathrm{ppm})$. UV spectra were obtained using a Varian Cary 50 diode-array spectrophotometer. Organic solvents used were carefully dried, and reactions were carried out under strictly anhydrous conditions, under argon. Ethyl 2,4-dinitrophenyl phosphate $\mathbf{4}$ was prepared according to literature precedent. ${ }^{3}$

\section{Kinetics}

Reactions were started by adding $30 \mu \mathrm{L}$ of a stock solution of the substrate $\left(2.0 \times 10^{-3} \mathrm{M}\right)$ in acetonitrile to $3 \mathrm{~mL}$ of reaction mixture containing a large excess (up to $1 \mathrm{M}$ ) of the nucleophile, assuring pseudo-first-order conditions. Strict first-order kinetics were observed for the reactions of the substrate, and reactions with nucleophiles were first order in both substrate and nucleophile. Reactions were followed at $25.0{ }^{\circ} \mathrm{C}$ and ionic strength $1.0 \mathrm{M}(\mathrm{KCl}$ added as required) for at least five half-lives, by monitoring the appearance of 2,4-dinitrophenolate at 362 and $398 \mathrm{~nm}$ on diode-array spectrophotometers, equipped with thermostated cell holders. The $\mathrm{pH}$ of the reaction mixture was measured at $25.0^{\circ} \mathrm{C}$ at the end of each run, using a digital $\mathrm{pH}$-meter equipped with a combined electrode (with integrated reference electrode) and a $\mathrm{Pt} 1000$ temperature sensor.

Observed first-order rate constants $\left(k_{\text {obs }}\right)$ were calculated by nonlinear least-squares fitting of the absorbance vs time curves, and correlation coefficients were always better than 0.999 . Second-order rate constants were obtained by linear regression analysis from slopes of plots of the observed first-order rate constants against the concentration of the nucleophile. Solutions of hydroxylamine nucleophiles were self-buffered between $\mathrm{pH} 4.0$ and 7.0 (standard aqueous $\mathrm{NaOH}$ (0.1 M; Merck) was added to aqueous hydroxylamine hydrochloride): measurements at pH 8 - 10 used carbonate buffers. However, carbonate buffers react with hydrogen peroxide to form the reactive peroxycarbonate anion, ${ }^{16}$ so reactions with hydrogen peroxide and its anion were self-buffered. Reactions with hydroxylamine at high $\mathrm{pH}$ were found to be very sensitive to ionic strength (Table 4), though the ionic strength effect is negligible at lower $\mathrm{pH}$.

We have attempted to allow for this effect as follows. Points measured at ionic strength 1.0 $\mathrm{M}$ contain (positive) contributions from the ionic strength effect, plus any specific ion effects. At each $\mathrm{pH}$ above 12 we measured rates at a series of higher ionic strengths, from 1.0 to $2.4 \mathrm{M}$. These rate constants (shown in Table 4) were linear in [ $\mathrm{KCl}]$, and so could be extrapolated, nominally, back to zero ionic strength. These extrapolated rate constants were used for the $\mathrm{pH}$ rate profile of Figure 1 above $\mathrm{pH}$ 12. This procedure makes the implicit assumption that $\mathrm{KOH}$, $\mathrm{KCl}$ and $\mathrm{KONH}_{2}$ have similar ionic strength effects on the rate of the reaction with $\mathrm{NH}_{2} \mathrm{O}^{-}$, and on its $\mathrm{p} K_{\mathrm{a}}$ : it cannot take account of specific ion effects on the reaction between the phosphodiester and hydroxylamine anions. 
Table 4. Effect of ionic strength $(\mu)$ on the reaction of $4(\mathrm{R}=\mathrm{Et})$ with the hydroxylamine anion $\left(0.4 \mathrm{M}\right.$ total hydroxylamine, water, $\left.25^{\circ} \mathrm{C}\right)$

\begin{tabular}{llllll}
\hline $\mathrm{pH}$ & $k_{\mathrm{obs}}, \mathrm{s}^{-1}, \mu=0$ & $k_{\mathrm{obs}}, \mathrm{s}^{-1}, \mu=1.0$ & $\mathrm{pH}$ & $k_{\mathrm{obs}}, \mathrm{s}^{-1}, \mu=0$ & $k_{\mathrm{obs}}, \mathrm{s}^{-1}, \mu=1.0$ \\
\hline 12.68 & 0.00485 & 0.00627 & 13.62 & 0.0419 & 0.058 \\
13.05 & 0.0113 & 0.0145 & 13.69 & 0.0475 & 0.069 \\
13.25 & 0.0188 & 0.0236 & 13.74 & 0.0532 & 0.0808 \\
13.40 & 0.0270 & 0.0349 & 13.80 & 0.0585 & 0.093 \\
13.52 & 0.0334 & 0.0453 & 13.85 & 0.0642 & 0.106 \\
\hline
\end{tabular}

\section{Products of the Reactions}

The reactions of phosphate diesters are slow enough that competition from nucleophilic aromatic substitution becomes significant for 2,4-dinitrophenyl derivatives. ${ }^{3}$ Though we are using nucleophiles expected to show exalted reactivity towards phosphorus, $\mathrm{S}_{\mathrm{N}}(\mathrm{Ar})$ reactions are themselves known to show modest $\alpha$-effects. ${ }^{17,18}$ Reactions with oxyanions produced the expected quantitative yields of 2,4-dinitrophenolate, but reactions with $4(\mathrm{R}=\mathrm{Et})$ of nucleophiles with primary or secondary amino groups could in principle give 2,4-dinitrophenylhydrazine or 2,4-dinitrophenylhydroxylamines (e.g. 7, Scheme 3), both with chromophores qualitatively similar to that of 2,4-dinitrophenolate near $400 \mathrm{~nm}$. So we analyzed the aromatic products from the reactions described above by ${ }^{1} \mathrm{H}$ and ${ }^{31} \mathrm{P}$ NMR. We find that hydroxylamine and its OMe and $\mathrm{N}$-monomethyl derivatives give comparable amounts of $\mathrm{N}$-aryl products, as shown for hydroxylamine in Scheme 3. Yields of the various $N$-aryl products were 40,50 and $60 \%$ for $\mathrm{NH}_{2} \mathrm{OH}, \mathrm{NH}_{2} \mathrm{OMe}$ and $\mathrm{MeNHOH}$, respectively: $\mathrm{Me}_{2} \mathrm{NOH}$ gives exclusively $\mathrm{P}-\mathrm{O}$ cleavage, as expected.

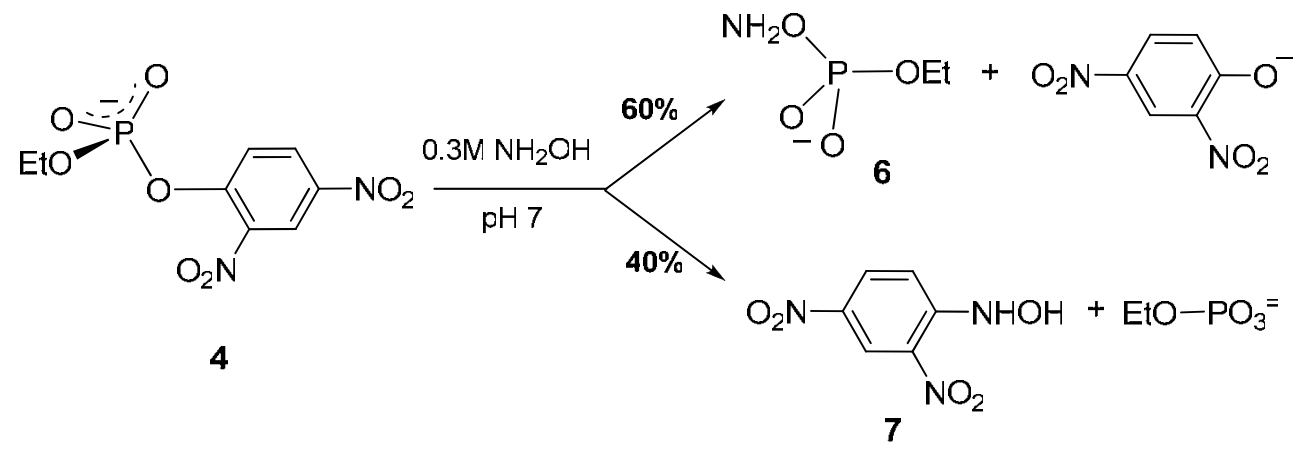

Scheme 3. The $S_{N} 2(P)$ and $S_{N} A r$ reactions of $4(R=E t)$ with hydroxylamine go at comparable rates. The products were identified from their NMR spectra (Table 5). Similar results were found for $\mathrm{NH}_{2} \mathrm{OMe}$ and $\mathrm{MeNHOH}$. A 1:1 mixture of two of them, $\mathrm{EtOPO}_{3}{ }{ }$ and $24 \mathrm{DNPO}^{-}$, is formed when $\mathbf{4}$ is hydrolyzed in alkali.

The second order rate constants in Table 3 have been corrected by these factors, to represent specifically attack on phosphorus. 
The reactions in Scheme 3 could be followed continuously by ${ }^{31} \mathrm{P}$ NMR spectroscopy. In $\mathrm{NaOH}$ solution at $\mathrm{pH} 13$ the disappearance of the signal of the reactant $4(\mathrm{R}=\mathrm{Et})$ at $-4.16 \mathrm{ppm}$ was accompanied by the appearance of a single multiplet at $5.49 \mathrm{ppm}$, assigned to the ethyl phosphate dianion. In the presence of hydroxylamine at $\mathrm{pH} 7$ two phosphorus-containing products were observed, in comparable amounts: ethyl phosphate, as observed on alkaline hydrolysis (chemical shift at $5.47 \mathrm{ppm}$ ), and a new signal at $\delta{ }^{31} \mathrm{P} 3.68$, assigned to EtO- $\mathrm{PO}_{2}^{-}$ $\mathrm{ONH}_{2}$ 6. The chemical shift assigned to 6 is consistent (deshielding by the 2,4-dinitrophenyl ring a typical $6 \mathrm{ppm}$ ) with the value of $-2.04 \mathrm{ppm}$ assigned to the product 2,4-dinitrophenyl-O- $\mathrm{PO}_{2}{ }^{-}$ $\mathrm{ONH}_{2}$ obtained from the similar reaction of hydroxylamine with bis(2,4-dinitrophenyl) phosphate by Domingos et al.; ${ }^{19}$ and with the value of $\delta=6.5$ found for the zwitterion $\mathrm{HO}-\mathrm{PO}_{2}{ }^{-}$ $-\mathrm{ONH}_{3}{ }^{+}$by Weiss et al. ${ }^{20}$ (Chemical shifts from the literature have been corrected where necessary to refer to $85 \%$ phosphoric acid.)

Table 5. NMR spectroscopic data for the products of the reaction of Scheme 3

\begin{tabular}{|c|c|c|}
\hline Cpd & $\delta^{1} \mathrm{H}$ NMR $(\mathrm{ppm})$ & $\delta^{31} \mathrm{P}$ NMR $(\mathrm{ppm})^{a}$ \\
\hline 4 & $\begin{array}{l}\delta 4.10 \text { (quintet, } 2 \mathrm{H}, J=7.15 \mathrm{~Hz}), 7.75\left(\mathrm{~d}, 1 \mathrm{H}, J_{\mathrm{ab}}=9.20\right. \\
\mathrm{Hz}, \mathrm{Ar}), 8.55\left(\mathrm{dd}, 1 \mathrm{H}, J_{\mathrm{ba}}=9.20 \mathrm{~Hz} \text { and } J_{\mathrm{bx}}=3.06 \mathrm{~Hz}, \mathrm{Ar}\right), \\
8.89\left(\mathrm{~d}, 1 \mathrm{H}, J_{\mathrm{xb}}=3.06 \mathrm{~Hz}, \mathrm{Ar}\right)\end{array}$ & -4.16 \\
\hline $\mathrm{EtOPO}_{3}{ }^{=}$ & $\delta 3.88$ (quintet, $2 \mathrm{H}, J=7.15 \mathrm{~Hz}$ ) & 5.47 \\
\hline $24 \mathrm{DNP}-\mathrm{O}^{-}$ & $\begin{array}{l}\delta 6.74\left(\mathrm{~d}, 1 \mathrm{H}, J_{\mathrm{ab}}=9.54 \mathrm{~Hz}, \mathrm{Ar}\right), 8.09\left(\mathrm{dd}, 1 \mathrm{H}, J_{\mathrm{ba}}=9.54\right. \\
\left.\mathrm{Hz} \text { and } J_{\mathrm{bx}}=3.06 \mathrm{~Hz}, \mathrm{Ar}\right), 8.85\left(\mathrm{~d}, 1 \mathrm{H}, J_{\mathrm{xb}}=3.06 \mathrm{~Hz}, \mathrm{Ar}\right)\end{array}$ & \\
\hline 6 & $\delta 3.98$ (quintet, $2 \mathrm{H}, J=7.15 \mathrm{~Hz}$ ) & 3.68 \\
\hline 7 & $\begin{array}{l}\delta 7.50\left(\mathrm{~d}, 1 \mathrm{H}, J_{\mathrm{ab}}=9.54 \mathrm{~Hz}, \mathrm{Ar}\right), 8.26\left(\mathrm{dd}, 1 \mathrm{H}, J_{\mathrm{ba}}=9.54\right. \\
\left.\mathrm{Hz} \text { and } J_{\mathrm{bx}}=2.38 \mathrm{~Hz}, \mathrm{Ar}\right), 9.00\left(\mathrm{~d}, 1 \mathrm{H}, J_{\mathrm{xb}}=2.38 \mathrm{~Hz}, \mathrm{Ar}\right)\end{array}$ & \\
\hline
\end{tabular}

${ }^{a}$ Relative to $85 \%$ phosphoric acid.

\section{Acknowledgements}

We are grateful to Capes, PRONEX, CNPq and FAPESC (Brazil) for support of this work.

\section{References}

1. Kirby, A. J.; Varvoglis, A. G. J. Chem. Soc., Section B 1968, 135.

2. Stahl, N.; Jencks, W. P. J. Am. Chem. Soc. 1986, 108, 4196.

3. Kirby, A. J.; Younas, M. J. Chem. Soc., Section B 1970, 1165.

4. Khan, S. A.; Kirby, A. J. J. Chem. Soc., Section B 1970, 1172.

5. Herschlag, D.; Jencks, W. P. J. Am. Chem. Soc. 1990, 112, 1951. 
6. Lewis, R. E.; Neverov, A. A.; Brown, R. S. Org. Biomol. Chem. 2005, 3, 4082.

7. Wolfe, S.; Mitchell, D. J.; Schlegel, H. B.; Minot, C.; Eisenstein, O. Tetrahedron Letters 1982, 23, 615.

8. Kirby, A. J.; Dutta-Roy, N.; da Silva, D.; Goodman, J. M.; Lima, M. F.; Roussev, C. D.; Nome, F. J. Am. Chem. Soc. 2005, 127, 7033.

9. Kirby, A. J.; Lima, M. F.; da Silva, D.; Roussev, C. D.; Nome, F. J. Am. Chem. Soc. 2006, 128, 16944.

10. Kirby, A. J.; Lima, M. F.; Tondo, D. W.; Nome, F. (unpublished work).

11. Hay, R. W.; Govan, N.; Norman, P. R. Transition Metal Chemistry 1998, 23, 133.

12. Simanenko, Y. S.; Popov, A. F.; Prokop'eva, T. M.; Karpichev, E. A.; Savelova, V. A.; Suprun, I. P.; Bunton, C. A. Russ. J. Org. Chem. 2002, 38, 1286.

13. Terrier, F.; Rodriguez-Dafonte, P.; Le Guevel, E.; Moutiers, G. Org. Biomol. Chem. 2006, 4, 4352.

14. Kirby, A. J.; Davies, J. E.; Brandão, T. A. S; da Silva, D.; Rocha, W. R.; Nome. F.J. Am. Chem. Soc. 2006, 128, 12374.

15. Jencks, W. P. Catalysis in Chemistry and Enzymology; McGraw-Hill: New York, 1969; p. 81.

16. Richardson, D. E.; Yao, H.; Frank, K. M.; Bennett, D. A. J. Am. Chem. Soc. 2000, 122, 1729.

17. Pietra, F.; Biggi, G. J. Chem. Soc. B. 1971, 44.

18. Moutiers, G.; Le Guevel, E.; Cannes, C.; Terrier, F.; Buncel, E. Eur. J. Org. Chem. 2001, 3279.

19. Domingos, J. B.; Longhinotti, E.; Bunton, C. A.; Nome, F. J. Org. Chem. 2003, 68, 7051.

20. Weiss, P. M.; Hermes, J. D.; Dougherty, T. M.; Cleland, W. W. Biochemistry 1984, 23, 4346. 